\title{
Knowledge and skill development of Bihar farmers on inland fisheries management: A terminal evaluation
}

\author{
APARNA ROY, B. K. DAS, GANESH CHANDRA, ARCHAN KANTI DAS AND R. K. RAMAN \\ ICAR-Central Inland Fisheries Research Institute, Barrackpore, Kolkata, India \\ e-mail: aparnandrister@gmail.com
}

\begin{abstract}
The state of Bihar in India has a huge potential in fisheries and the research institutes of Indian Council for Agricultural Research (ICAR) are involved in building capacity of the fish farmers of the state. Since 2012-13 to 2014-15 about 1279 fish farmers from 21 districts of Bihar State were trained under the Department of Fisheries/Agricultural Technology Management Agency schemes by ICAR-Central Inland Fisheries Research Institute on inland fisheries management. An ex-post facto study was undertaken to measure the effectiveness of these training programmes. Data were collected from 400 trainees from six different districts of Bihar using a semi-structured interview schedule. The Training Effectiveness Index (TEI) was developed and the results of the study indicated that the logistic regression analysis with socio-economic variables like main occupation, land holding, membership in organisations had positive and significant effect on training effectiveness. The overall effectiveness of training was found to be $87.86 \%$ which was recorded under the high effectiveness category. The results also revealed that $44.8 \%$ of the trainees were young and they also had positive effect on training effectiveness. About $53 \%$ of the farmers perceived that the training situation provided to them was highly satisfactory. The farmers also perceived that these trainings helped them to increase their knowledge and skill, enhance entrepreneurial ability and also motivated them to initiate new enterprises.
\end{abstract}

Keywords: Bihar, Inland Fisheries, Knowledge, Management, Skill, Training effectiveness

\section{Introduction}

Development of a nation is the sum total of physical, natural and human resource development and among all these human resource is the root, which helps to bring desired impact in the country's development. Abundant physical or natural resources may lie unutilised or get wasted if human resource is not skilled or developed for its effective utilisation. As per World Bank report (World Bank, 1990) human resource development is a key component to reduce poverty and it helps to improve socio-economic development. To develop human resource, knowledge and skill is very much essential and that can be through training; as training is a systematic effort to increase knowledge, improve skill, inculcate appropriate attitudes and develop desired attributes. Fisheries sector has an important role in overall development of the state of Bihar, India. The state is endowed with a variety of natural water resources viz., rivers and associated water bodies like floodplain wetlands (oxbow lakes, meanders, seasonal floodplains), reservoirs, ponds and tanks. The state is endowed with $2800 \mathrm{~km}$ stretch of rivers; 2,00,000 ha of chaurs and floodplain wetlands; 9,000 ha of oxbow lakes or mauns; 25,000 ha of reservoirs and 90,000 ha of ponds and tanks. The maximum utilisation of these water resources can fetch prosperity for the state and ensure food and nutritional security. Appropriate inland fisheries management can bring out new avenues for self-employment and entrepreneurial opportunities for sufficient and sustainable wealth generation for rural populace of the state. Since 2008, Department of Fisheries, Government of Bihar has introduced several schemes for skill development of fish farmers, among them the most important scheme is capacity building and training of the fish farmers on recent advances in inland fisheries management to be conducted in institutes outside Bihar. ICAR-Central Inland Fisheries Research Institute (ICAR-CIFRI) is a premier research organisation situated in Barrackpore, West Bengal and is prominent in Asia in the field of inland fisheries research, extension and training and mandated to create awareness, provide training and consultancy in inland open-waters. Since 2012-13 to 2014-15, about 1279 fish farmers from 21 districts of Bihar State were trained under the Department of Fisheries/Agricultural Technology Management Agency schemes by ICAR-CIFRI on the theme of Inland Fisheries Management viz., flood plain wetland management, enclosure culture, fish disease management, utilisation of derelict waters, soil and water chemistry and feeding management. Training is a process which results in changes 
of attitudes through development of knowledge and skill in accordance with specific objectives. Evaluation of the impact of training is also necessary which can be done though systematic collection of data or information for and about a training activity which can then be used for guiding decision making and for assessing relevance and effectiveness of various training components (Raab, 1987). In the present study, an attempt was made to use terminal evaluation to determine the effectiveness of the trainings imparted to fish farmers of Bihar during 2012-13 to 2014-15 by ICAR-CIFRI on inland fisheries management for securing livelihoods and generating employment opportunities for the rural populace of Bihar.

\section{Materials and methods}

Terminal evaluation is concerned with learners' performance and its primary objective was to determine the degree to which the intended objectives and goals have been fulfilled. Two general methods were used for terminal evaluation, measurements of change in KSAOs and measurement of trainee perceptions about training activity through questionnaire, rating scale, checklists and other tools (Mishra,1990). A total of 400 trainees were randomly selected and they were interviewed with semi-structured interview schedule and Training Effectiveness Index (TEI) was calculated for terminal evaluation. Data were collected during 2012-13 to 2014-15. 'Four point continuum scale' was used to measure the perception of the trainees on different aspects of training. The TEI was calculated using the formula of Singh and Singh (2014) as:

$$
\begin{aligned}
& \text { TEI }=\frac{\text { TS obtained by respondents }}{\text { Maximum possible scores }} \times 100 \\
& \text { where, TS }=\text { Training score }
\end{aligned}
$$

The relation of socio-economic parameters with the training effectiveness was ascertained through Logistic Regression Analysis (LRA). The dependent and independent variables and their measurements are given in Table 1.

\section{Results and discussion}

\section{Socio-economic profile of the farmers}

The profile of farmers in the present study highlights their salient characteristics as these characteristics were assumed to influence their perception regarding

\begin{tabular}{|c|c|}
\hline Variables & Measurement \\
\hline \multicolumn{2}{|l|}{ Independent variables } \\
\hline Age & Direct questioning \\
\hline Education & Direct questioning \\
\hline Occupation & Direct questioning \\
\hline Family size and family type & Direct questioning \\
\hline Land/pond holding & Direct questioning \\
\hline Family income & Direct questioning \\
\hline $\begin{array}{l}\text { Social participation (Membership in any } \\
\text { organisation) }\end{array}$ & Schedule developed \\
\hline \multicolumn{2}{|l|}{ Dependent variable } \\
\hline Effectiveness of training & Schedule developed \\
\hline \multicolumn{2}{|c|}{$\begin{array}{l}\text { effectiveness of the training. The variables under } \\
\text { investigation were analysed critically and primary } \\
\text { descriptions are presented. }\end{array}$} \\
\hline \multicolumn{2}{|c|}{$\begin{array}{l}\text { The study revealed that majority of the fish farmers } \\
(44.8 \% \text { ) belonged to young age group ranging from } \\
18-30 \text { years; } 28.96 \% \text { belonged to age group of } 31-40 \\
\text { years and only } 16 \% \text { of the farmers were more than } 50 \\
\text { years of age. As almost } 45 \% \text { of the trainees were young, } \\
\text { enhancement of skill and knowledge during the training } \\
\text { was expected (Table } 2 \text { ). }\end{array}$} \\
\hline \multicolumn{2}{|c|}{ Table 2. Distribution of the respondents according to age } \\
\hline Age composition (yr) & Respondents \\
\hline $18-30$ & $79(44.8 \%)$ \\
\hline $31-40$ & $16(28.96 \%)$ \\
\hline $41-50$ & $1(15.17 \%)$ \\
\hline$>51$ & $4(11.11 \%)$ \\
\hline
\end{tabular}

Table 1. Variables and measurements

Among the trainees it was found that $35.41 \%$ were graduates and $9.65 \%$ were having post-graduate degree and $2.75 \%$ were functionally literate (Table 3 ). Higher educational status was noticed among the young age group trainees. Functional literacy was prevalent among the trainees above 50 years of age. Background, educational qualifications and literacy skills are highly related. But sometimes, from a theoretical perspective, due to presence of third variables, this relationship may vary (Massing and Schneider, 2017).

Majority of the respondents (72\%) among the trainees were engaged in agriculture and it was their main occupation. Only $4 \%$ of the respondents were found to be landless labourers. About $24 \%$ of the trainees were involved in fisheries and it was their main business (Fig. 1). Trainees' attributes and attitudes may influence the

Table 3. Distribution of respondents based on educational status

\begin{tabular}{llllll}
\hline Educational status & Functionally literate & Primary level & Secondary level & Graduate & Post-graduate \\
\hline Bihar farmers & $11(2.75 \%)$ & $60(15.17 \%)$ & $149(37.24 \%)$ & $141(35.17 \%)$ & $39(9.65 \%)$ \\
\hline
\end{tabular}




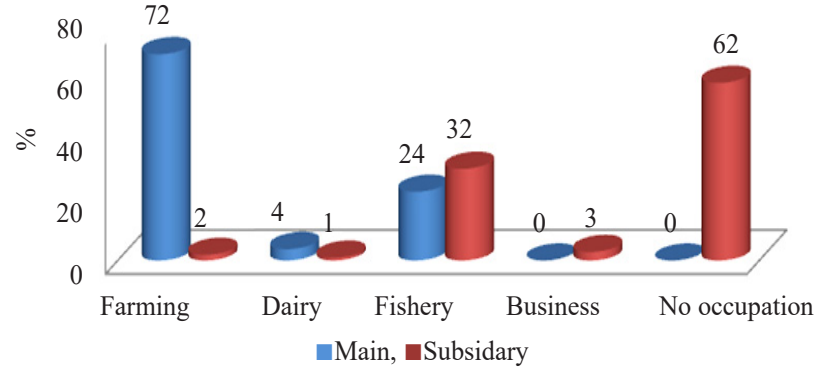

Fig. 1. Occupational distribution of the respondents

effectiveness of training (Noe, 1986). So, the occupational diversification among trainees may have influence on training effectiveness.

Only $5 \%$ of the respondents were in service with organisations. Business or independent profession/others (poultry and goatary) was being carried out by $42 \%$ of the total respondents; whereas $26 \%$ of the respondents carried out dairying as their subsidiary occupation. Hence, it could be concluded that majority of the farmers were engaged in agriculture.

About $48 \%$ of the farmers did not have any involvement in social organisations. Only $19 \%$ of the sampled farmers were members of cooperative societies and $13 \%$ of them were members of farmers' clubs, whereas $8 \%$ were members of fish production group (Fig. 2).
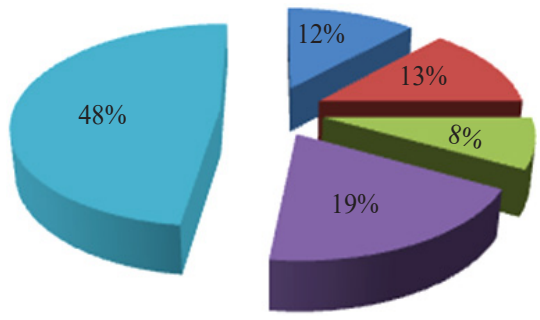

nGOs; - Farmers club; $\quad$ Fish production groups;

- Cooperative societies; $\square$ No involvement

Fig. 2. Farmer's involvement in organisations

\section{Effectiveness of the training programmes}

Farmers' training is an intensive learning activity for a group of selected farmers, assisted by competent trainers to understand and practice the skills required in the adoption of technology at a place where appropriate facilities exist and at a time and duration considered suitable by farmers (Okwu and Ejembi, 2005). Effectiveness of the training programme is an essential indicator of terminal evaluation. Terminal evaluation helps to assess the usefulness of training by the implementing organisation as well as to the donors. In the present study, it was measured on a four point continuum ranging from high to very low effectiveness. Among the respondents, $48 \%$ reported that the training was highly effective, $27 \%$ of the trainees reported that effectiveness was at a medium level and $12 \%$ of the beneficiary farmers stated the training programmes as very less effective (Table 4). Meta-analysis of seventy training programmes by Scott (2004) revealed that, well designed creativity training programs typically induce gains in performance and cognitive skills. The overall TEI was calculated based on individual score and it was found to be $71.3 \%$, which implies that trainings conducted were successful in terms of imparting knowledge, skill and changes in attitude and attribute of the trainees and were rated as medium to highly effective.

Table 4. Distribution of respondents based on effectiveness of training programmes

\begin{tabular}{ll}
\hline Category for effectiveness & No. of farmers (\%) \\
\hline Very low (10-15) & 12 \\
Low (15-20) & 13 \\
Medium (20-25) & 27 \\
High (25-30) & 48 \\
\hline
\end{tabular}

Perception of beneficiary farmers on different aspects of training programme

Most of the farmers (46\%) perceived that the course content on which training provided to them were highly relevant. Almost $54 \%$ of the farmers perceived that designing of the course material is very effective as theory as well as practical and field exposure visits were also included in the training curriculum. About $67 \%$ of the trained farmers perceived that faculty of the training programmes are highly effective as they are very interactive and use audiovisual aids in local language. Beneficiary farmers (92\%) were satisfied about the physical facilities available in the institute for the training. However, $6 \%$ of the farmers perceived that the practical facilities for the training were not effective, whereas 59\% of the farmers perceived as highly effective. Overall $83 \%$ of the trainees expressed very high level of satisfaction from the trainings in terms of overall training facilities, course curriculum, faculty and exposure visits. This finding is in line with the study on farmers' perception towards effectiveness of trainings organised by Krishi Vigyan Kendras (KVKs) at Uttarakhand which revealed that majority of the KVK beneficiaries (50\%) had favourable perceptions towards training programmes (Ranjan, 2017). A study by Ahmad et al. (2012) revealed that majority of respondents $(63.42 \%)$ reported that training programme was fully based on their needs and was effective for them.

The results (Table 5) also depict an effective learning situation (Fig. 3) as all essential elements for promoting learning i.e., learners, teachers, subject matter, teaching 
Table 5. Distribution (\%) of beneficiary farmers based on perception on different aspects of training programme

\begin{tabular}{lllll}
\hline $\begin{array}{l}\text { Perceptional factor } \\
\text { dimension }\end{array}$ & Very high & High & Medium & Low \\
$\begin{array}{l}\text { Relevance of course } \\
\text { contents }\end{array}$ & 46 & 30 & 18 & 6 \\
$\begin{array}{l}\text { Designing of the course } \\
\text { and teaching material }\end{array}$ & 54 & 21 & 21 & 4 \\
$\begin{array}{l}\text { Faculty } \\
\text { Classroom facility }\end{array}$ & 67 & 33 & - & - \\
$\begin{array}{l}\text { Practical session/facility } \\
\text { Field exposure }\end{array}$ & 12 & 59 & - & - \\
$\begin{array}{l}\text { Overall satisfaction from } \\
\text { training }\end{array}$ & 83 & 42 & 26 & 6 \\
\hline
\end{tabular}

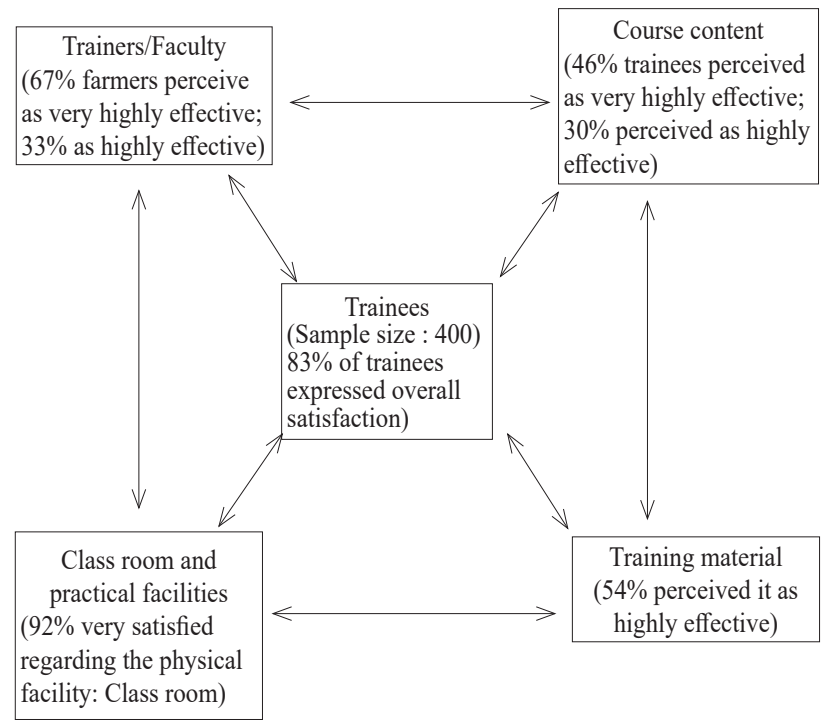

Fig. 3. Effective learning/training situation

materials and physical facilities (Leagans,1961) are present in a dynamic relationship with one another. Appropriate learning situation gives quality learning environment and favourable situation to learn. Learning is an important function of our cognitive system which brings desirable and relatively permanent change in behaviour. The learners perceived that $67 \%$ faculty /trainers are very highly effective and the course content is also perceived as very highly relevant by $46 \%$ of the trainers or learners. The trainers were also highly satisfied with class room facility $(92 \%)$ and practical facilities. The course material
Table 6 . Training benefits as perceived by the beneficiaries

\begin{tabular}{llll}
\hline Training benefits & High & Moderate & Low \\
\hline Increase in knowledge & $47 \%$ & $39 \%$ & $14 \%$ \\
Development of skills & $16 \%$ & $59 \%$ & $25 \%$ \\
Enhancement of & $36 \%$ & $43 \%$ & $21 \%$ \\
entrepreneurial ability & & &
\end{tabular}

or teaching material developed for the trainees was also perceived as highly effective by $54 \%$ of the trainees.

\section{Training benefits as perceived by the beneficiaries}

The study revealed that (Table 6) training on inland fisheries management helps the beneficiaries to increase their knowledge (46\% reported high, 39\% moderate and $14 \%$ low) on various issues of inland fisheries management like wetland management; enclosure culture; disease management and conservation aspects. Skill is very important as it determines the ability to execute plans. Fifty-nine percentage of training beneficiaries believed that they have gained moderate improvement in their skills like fish feed preparation, water quality analysis, disease identification and record keeping. About $36 \%$ of the trainees reported that the trainings effectively contributed to enhance their entrepreneurial ability in the field of inland fisheries like feed mill establishment and integrated wetland development. These inferences are in agreement with the findings of the study conducted by Singh and Singh (2014) at Patna and Muzaffarpur districts of Bihar State where $58.3 \%$ farmers perceived that they were highly benefited in terms of increase in knowledge followed by gain in skills (48.3\%) and $15 \%$ farmers were willing to start new enterprise as a result of training.

Logistic regression analysis showed that the socio-economic variables like main occupation i.e., agriculture, age (18-30) of the farmers, land and pond holdings of the farmers and membership in organisations (NGOs, Cooperative societies and Groups) have positive and significant relationship with training effectiveness (Table 7).

The findings of the study suggested that the trainings provided to the farmers from Bihar were imperative and have brought about positive impact leading to increase in knowledge level of the farmers. One third of the farmers

Table 7. Estimates using logistic regression analysis

\begin{tabular}{lllll}
\hline Parameter & Estimate & Standard error & Wald Chi-Square & $\mathrm{p}>\chi^{2}$ \\
\hline Main occupation (Agriculture) & 1.7449 & 0.5308 & 10.8058 & 0.0010 \\
Young age (18-30 yr) & 0.4189 & 0.2371 & 3.1208 & 0.0503 \\
Land /Pond holding & 0.1140 & 0.0622 & 3.3583 & 0.0609 \\
Membership in organisations & 0.1487 & 0.0802 & 3.4388 & 0.0637 \\
\hline
\end{tabular}


felt that training has enhanced their entrepreneurial ability. The study has identified the weak links in the training programme such as inadequate field visits and limitations in practical facilities. There is scope for improvement through increase in practical facilities and more field exposure visits to the trainee farmers during future training programmes. More information is also needed to assess the ex-post-facto impact of training programmes in terms of adoption of different practices of inland fisheries management and their entrepreneurial capability in handling real farming situation.

\section{Acknowledgements}

Authors are indebted to Mr. Atanu Das, Technical personnel of ICAR-CIFRI, Barrackpore for assistance in collection of data.

\section{References}

Ahmad, N., Singh, S.P. and Parihar, P. 2012. Farmers assessment of KVK training programme. Economic Affairs, 57(2): 165-168.

Leagans, J. P. 1961. Characteristics of teaching and learning in extension education, 15. Extension Education in Community Development, Directorate of Extension, Govt. of India, New Delhi.

Massing, N. and Schneider, S. L. 2017. Degrees of competency: the relationship between educational qualifications and adult skills across countries. Large scale Assessments in Education, 5(1): 6.

Misra, D. C. 1990. New directions in extension training: a conceptural framework. Directorate of Extension, Govt. of India. New Delhi, 238 pp.

Noe, R. A. 1986. Trainees' attributes and attitudes: Neglected influences on training effectiveness. Acad. Manage. Rev., 11(4): 736-749.

Okwu, J. O. and Ejembi, A. S. 2005. Essentials of a successful farmer training programme in Agricultural Extension in Nigeria. Proceedings of the $10^{\text {th }}$ Annual National Conference, AESON, 14-17 June, 2005, Nigeria, p. 1-5.

Raab, R. T., Swanson, B. E., Wentling, T. L. and Clark, C. D. 1987. A trainer's guide to evaluation. FAO, Rome., p. 20-25.

Ranjan, R., Ansari, M. A., Verma, A. P., Shekhar, S. and Rashit, S. 2017. Farmers' perception towards effectiveness of Krishi Vigyan Kendras (KVKs): A study in Uttarakhand, India. Int. J. Curr. Microbiol. App. Sci., 6(3): 878-890.

Scott, G., Leritz, L. E. and Mumford, M. D. 2004. The effectiveness of creativity training: A quantitative review. Creativity Res. J., 16(4): 361-388.

Singh, D. K. and Singh, P. 2014. Effectiveness of training programmes under Agricultural Technology Management Agency in Bihar. Ind. Res. J. Ext. Educ., 14(1): 93-95.

World Bank 1990. World Development Report 1990. Oxford University Press, New York. 